\title{
膝十字靱帯損傷の定量的X線診断法（II）
}

\author{
九州大学医学部整形外科 \\ 福島一彦・緒方公介

\section{The Stress Roentgenographic Measurement for the Diagnosis of Cruciate Insufficiency of the Knee Joint-2nd Report} \\ by \\ Kazuhiko Fukushima and Kosuke Ogata \\ Department of Orthopaedic Surgery, Faculty of Medicine, \\ Kyushu University
}

\begin{abstract}
The anterior/posterior displacement in cruciate insufficient knee joint was measured. Both drawer tests were performed at 30 degrees of flexion in addition to 90 degrees of flexion, and the deta were statistically analyzed. The methods of loading a quantitative stress on the knee joint and a roentgenographic measurement were previously reported. In anterior cruciate insufficient knee, the anterior displacement was larger at 30 degrees of flexion than at 90 degrees. In posterior cruciate insufficient knee, on the contrary, the posterior displacement was larger at 90 degrees of flexion. The mean difference between complete and partial tear of each cruciate ligament was not statistically significant.
\end{abstract}

\section{はじめに}

膝十字勒帯損傷を外来にて客観的に診断するために, われわれは不全膝に定量的ストレスを加えてX線撮影 を行い，そのX線像上での変位量を計測する方法を用 いている6).今回，これまでにこの方法を用いて計測し た症例の值に統計処理を施し，正常膝と不全膝との境 界域などに関して検討を加えてみた。

$$
\text { 方法 }
$$

1.ストレス方法

ストレス器械は，市販の自転車を改造したものを用 い, 30 度抢よび 90 度屈曲位にて前方, 後方ストレスと も 73.5 ニュートンの定量的ストレスを加えた。なお下 腿回旋の固定は行っていない（図 1).

2. X線計測法

まず Medial Tibial Plateauに平行に Base Line を 引き, Base Line に直交し大腿骨の内, 外顆の最後端 の中点を通る Line F と脛骨の内, 外顆の最後端の中点 を通る Line $\mathrm{T}$ 間の距離 $\mathrm{D}$ を計測した。この值が脛骨の
大腿骨に対する変位量である.ただし脛骨の Line T が 大腿骨の Line Fより前方にあるときをプラス, 逆をマ イナスとした(図 2).

\section{3. 対象}

表に示すとうりである（表 1 ).

\section{結果および考察}

1. 正常膝について

ノンストレス，前方ストレス，後方ストレス時の変 位量をグラフに示した (図 3-A，表 2 ). 30 度と 90 度屈曲時の Laxity を比較するため, ストレス時の值か らノンストレス時の值を引いた相対変位量（平均值の み)を計算すると, 前方ストレスでは, 30 度で $1.88 \mathrm{~mm}$, 90 度で $1.84 \mathrm{~mm}$ とほぼ同じ值であるが, 後方ストレス では, 30 度で $2.58 \mathrm{~mm}, 90$ 度で $1.58 \mathrm{~mm}$ と 30 度のほ うが大きかった。すなわち正常膝の前方 Laxity にさほ ど差はないが, 後方 Laxity は 30 度のほうが大きいこ とがわかった。

わ机れの值を Kennedy や Torzilli らの值と比較し てみた ${ }^{2) 5}$ (表 3 ：值はいずれもストレス時とノンストレ 

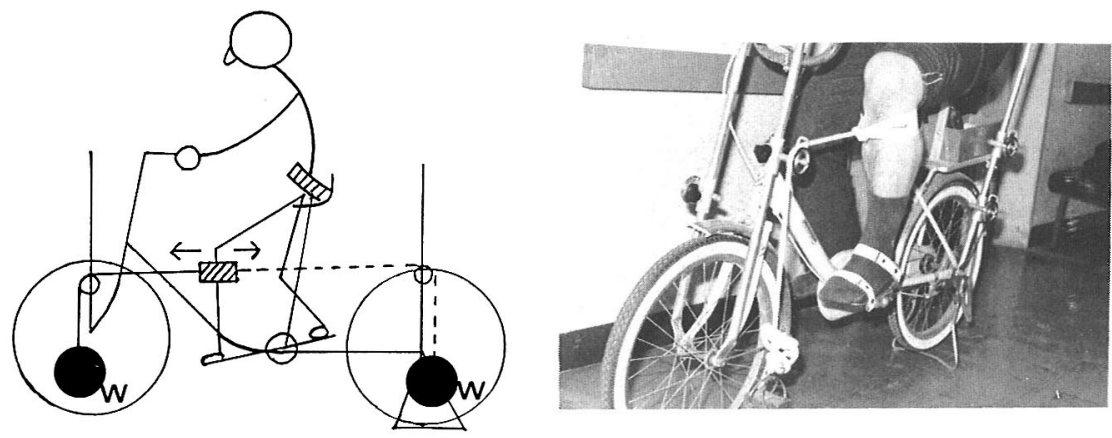

図 1 定量的ストレス撮影法

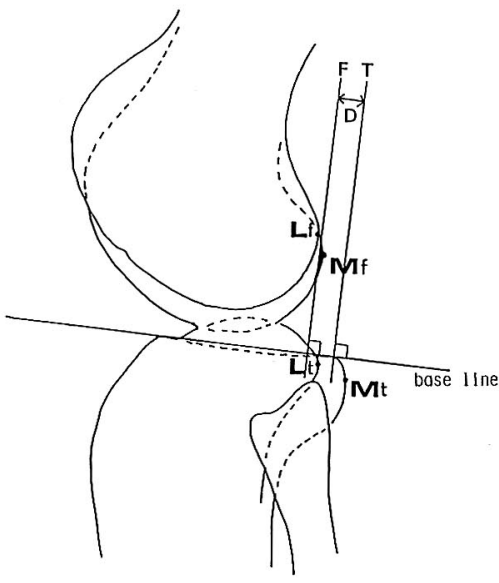

図 2 X線計測法

\begin{tabular}{|c|c|c|c|c|c|c|c|}
\hline 計測症例 & & & & 左 & 右 & 男性 & 女性 \\
\hline 正 $\underset{(25 人)}{\text { 常 }}$ 膝 & $\begin{array}{l}\text { 前方引出 } \\
\text { 後方引出 }\end{array}$ & $\begin{array}{l}30 \\
90 \\
30 \\
90\end{array}$ & $\begin{array}{l}\text { 35膝 } \\
33 \text { 膝 } \\
30 \text { 膝 } \\
30 \text { 滕 }\end{array}$ & $\begin{array}{l}18 \\
16 \\
14 \\
14\end{array}$ & $\begin{array}{l}17 \\
17 \\
16 \\
16\end{array}$ & $\begin{array}{l}31 \\
29 \\
29 \\
29\end{array}$ & $\begin{array}{l}4 \\
4 \\
1 \\
1\end{array}$ \\
\hline $\begin{array}{l}\text { ACL 損傷膌 } \\
\text { (17人) }\end{array}$ & 前方引出 & $\begin{array}{l}30 \\
90\end{array}$ & $\begin{array}{r}\text { 9月漛 } \\
17 \text { 滕 }\end{array}$ & $\begin{array}{l}3 \\
8\end{array}$ & $\begin{array}{l}6 \\
9\end{array}$ & $\begin{array}{l}5 \\
9\end{array}$ & $\begin{array}{l}4 \\
8\end{array}$ \\
\hline $\begin{array}{c}\text { PCL 損傷膝 } \\
\text { (15人) }\end{array}$ & 後方引出 & $\begin{array}{l}30 \\
90\end{array}$ & $\begin{array}{r}\text { 9月脊 } \\
15 \text { 滕 }\end{array}$ & $\begin{array}{l}5 \\
9\end{array}$ & $\begin{array}{l}4 \\
7\end{array}$ & $\begin{array}{r}9 \\
15\end{array}$ & $\begin{array}{l}0 \\
0\end{array}$ \\
\hline
\end{tabular}

表 1 計測症例

ス時との相対変位量である). 30 度での計測はわれわれ のみしか行っていないが，われわれの計測条件にもっ とも近いのは Torzilli らの 90 度屈曲 67 ニュートンで
あり,前方変位量はわれわれの $1.84 \mathrm{~mm}$ に対し彼らは $2.02 \mathrm{~mm}$, 後方変位量はわれわれの $1.58 \mathrm{~mm}$ に対し彼 らは $1.68 \mathrm{~mm}$ と弱干大きい.

2. 不全滕について

(ACL 不全膝) グラフは 30 度, 90 度屈曲時におけ る前方ストレス時の変位量を表わし, デー夕は 30 度, 90 度とも同一の 6 症例のものである(図 $3-\mathrm{B}$, 表 2 )。 正常膝と不全膝との差をみると, 30 度では $8.83 \mathrm{~mm}$, 90 度では $5.19 \mathrm{~mm}$ と 30 度屈曲時のほうが大きい.す なわ方 ACL 不全では, 30 度のほうが正常膝との差が大 きいので鑑別がしやすく， Lachmann test の ACL 不 全膝の診断における有用性が高いことがわかる.

(PCL 不全膝) グラフは後方ストレス時の変位量を 表わし, データは 30 度, 90 度とも同一の 6 症例のもの である(図 $3-\mathrm{C}$, 表 2)。正常膝と不全膌との差をみ ると, 30 度では $9.21 \mathrm{~mm}, 90$ 度では $11.4 \mathrm{~mm}$ と ACL 不全とは逆に 90 度のほうが大きい。すなわち PCL 不 全では, 90 度のほうが正常膝との鑑別がしやすいこと がわかる。また 30 度, 90 度共に ACL 不全膝の值より 大きい.これはストレス時の筋緊張の関与が後方スト レス時のほうが少いためと考えられる。

(Complete tear と Partial tear の比較) 90 度屈曲 にて Complete tear と Partial tear との変位量に関す る比較を行ったが片側 $5 \%$ 以内の有意差を認めなかっ た(表 2 )。なお鞋帯の連続性がないものを Complete, 一部分でも連続性があるものを Partial とし, ACL 不 全では Complete tear 6 例, Partial tear 6 例を用い, PCL 不全では Complete tear 4 例, Partial tear 3 例 を用いた，有意差を認めなかった理由としては，症例 数が少いことや, 非麻酔下 73.5 二ュートンのストレス 

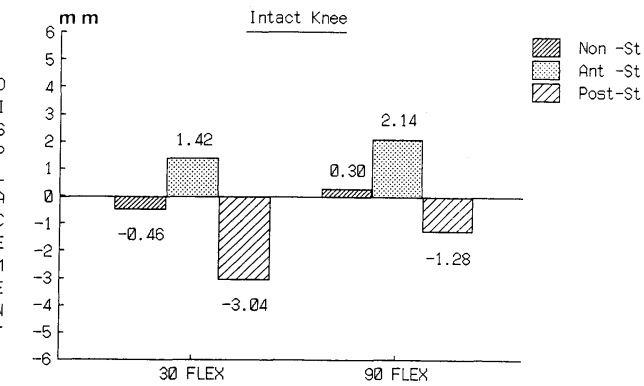

LOAD : $73.5 \mathrm{~N}$

A

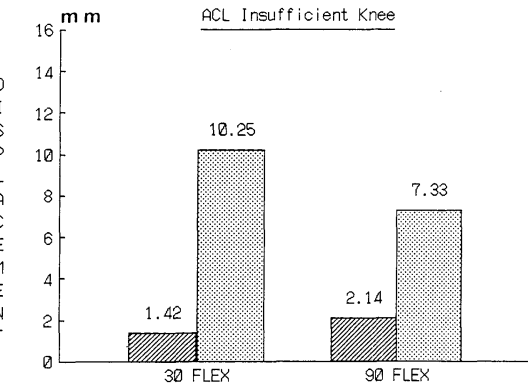

ACL

LOAD : $73.5 \mathrm{~N}$

\section{Intact Knee}

\begin{tabular}{c|c|c}
\hline \hline & $\begin{array}{l}\text { Posterior } \\
\text { Displacement }\end{array}$ & $\begin{array}{l}\text { Anterior } \\
\text { Displacement }\end{array}$ \\
\hline 30 Flex. & $-3.04(2.24)$ & $1.42(1.95)$ \\
\hline 90 Flex. & $-1.28(1.54)$ & $2.14(1.80$ \\
\hline
\end{tabular}

(Non stress) 30 Flex : $-0.46(2.14)$, 90 Flex : $0.30(1.06)$

Insufficient Knee

\begin{tabular}{l|c|c}
\hline \hline & $\begin{array}{l}\text { PCL Posterior } \\
\text { Displacement }\end{array}$ & $\begin{array}{l}\text { ACL Anterior } \\
\text { Displacement }\end{array}$ \\
\hline 30 Flex. & $-12.25(2.33)$ & $10.25(4.39)$ \\
\hline 90 Flex. & $-12.75(2.95)$ & $7.33(2.36)$ \\
\hline Complete & $-12.50(3.19)$ & $7.67(2.02)$ \\
\hline Partial & $-12.75(1.52)$ & $6.00(3.42)$ \\
\hline
\end{tabular}

表 2 正常膝, 不全膝のストレス時の変位量 脛骨の Line T が大腿骨の Line F より前方にある 時をプラス，逆をマイナスとする。

Ours

\begin{tabular}{lll|l|l}
\hline \hline & & $\begin{array}{l}\text { Posterior } \\
\text { Displacement }\end{array}$ & $\begin{array}{l}\text { Anterior } \\
\text { Displacement }\end{array}$ \\
\hline $73.5 \mathrm{~N}$ & 30 & Flex. & 2.58 & 1.88 \\
\hline $73.5 \mathrm{~N}$ & 90 & Flex. & 1.58 & 1.84 \\
\hline
\end{tabular}

Torzilli \& Insall's

\begin{tabular}{|c|c|c|}
\hline & $\begin{array}{l}\text { Posterior } \\
\text { Displacement }\end{array}$ & $\begin{array}{l}\text { Anterior } \\
\text { Displacement }\end{array}$ \\
\hline 67N $90 \quad$ Flex. & $1.68(1.28)$ & $2.02(1.37)$ \\
\hline
\end{tabular}

Kennedy \& Fowler's

\begin{tabular}{|c|c|c|}
\hline & $\begin{array}{l}\text { Posterior } \\
\text { Displacement }\end{array}$ & $\begin{array}{l}\text { Anterior } \\
\text { Displacement }\end{array}$ \\
\hline $196 \mathrm{~N} 90$ Flex. & $1.65(0.80)$ & $3.5 \quad(1.70)$ \\
\hline $134 \mathrm{~N} 90$ Flex. & $3.24 \quad(2.20$ & $3.79(2.04)$ \\
\hline
\end{tabular}

表 3 正常膝のストレス時のノンストレス時との相対 変位量 


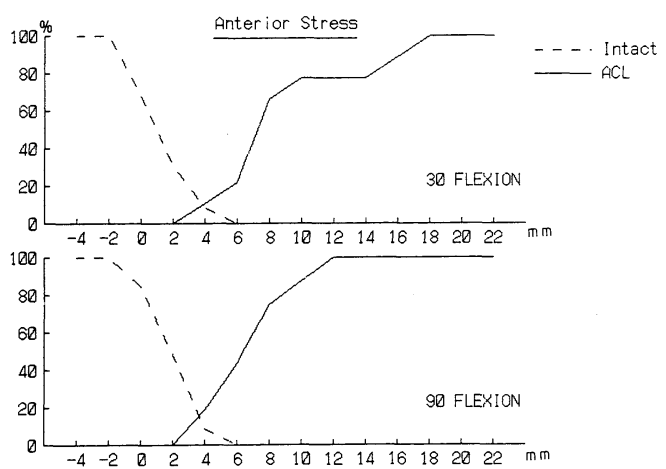

A

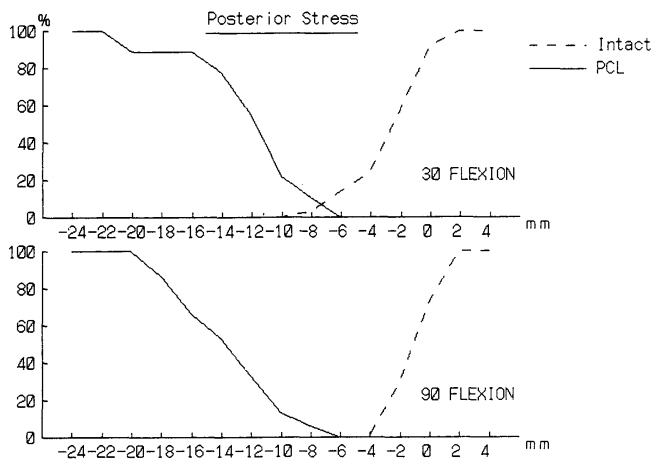

B

図 4 ストレス時の変位童の累積相対度数を示すグラ ᄀ

$A$ ：前方ストレス時 $B$ ：後方ストレス時

では最大引き出しができないことおよび Partial tear と 言ってもほぼ機能を排絶しているものも多いことなど が考えられる。

2 . 正常膝と不全膝の境界域について

正常膝と不全膝の境界を検討するため度数分布表を 作成し，それをグラフ化してみた(図 $4-\mathrm{A} ， \mathrm{~B}$ )。グ ラフは, 横軸に変位量, 縦軸に累積相対度数を\%で示 している。累積相対度数は, 正常膝では変位量が大き いほうより累積し, 不全膝では小さいほうより累積し ている.グラフをみると, ACL 不全の度数が正常を上 回るのは，30, 90 度とも約 $4 \mathrm{~mm}$ 付近であるが，4 ら $6 \mathrm{~mm}$ の間は両者が混在しておりこの範囲での鑑別 が難しいことがわかる(図 4-A).

次に PCL 不全についてみると, 累積相対度数は 30 度
では正常膝の変位量が大きく, - 6 から-10 mm の間で 両者が混在しているが, 90 度ではー 4 から-6 mmの 間は両者共度数 0 であり, 90 度での鑑別が容易である ことがわかる(図 $4-\mathrm{B}$ )。

\section{ま と め}

1. 自転車を改造した器械を用いて, 正常膝と十字 䩲帯不全膝に対し $73.5 \mathrm{~N}$ の定量的ストレスを加え, 30 度および 90 度屈曲位での X 線撮影を行った。

2. 前回報告したX線計測法を用いて, 脛骨と大腿 骨間の変位量を計測した。

3. 正常膝の場合, 前方引き出し量は 30 度と 90 度 ともほぼ等しかったが, 後方引き出し量は 30 度のほう が大きい傾向にあった。

4. 不全膝の場合, ACL 不全では 30 度のほうが, PCL 不全では 90 度のほうが引き出し量が大きい傾向に あった。

5. Partial tear と Complete tear との比較では有 意差を認めなかった。

6. 累積相対度数を計算し, 各変位量における正常 膝と不全膝の頻度をグラフ化し境界域を示した。

\section{参 考 文 献}

1) Jacobsen, Klaus: Stress Radiographical Measurement of the Anteropostererior, Medial and Lateral Stability of the Knee Joint. Acta Orthop. Scandinavica, 47 : 335-344, 1976.

2) Kennedy, J.C., and Fowler, P. J.: Medial and Anterior Instability of the Knee. An Anatomical and Clinical Study Using Stress Machines. J. Bone and Joint Surg., 53-A : 1257-1270, Oct. 1971.

3) Markolf, K. L., Graff-Radford, A., and Amustutz, H. C. : In Vitro Knee Stability-A Quantitative Assessment Using an Instrumented Clinical Testing Aparatus. J. Bone and Joint Surg., 60-A : 664-674, July 1978.

4) Muller, W.: The Knee-Form, Function, and Ligament Reconstruction. Springer-Verlag Berlin Hidelberg New York 1983.

5) Torzilli, P. A., Greenberg, R. L. and Insall, J. : An in Vitro Biomechanical Evaluation of Anterior-Posterior Motion of the Knee. J. Bone and Joint Surg., 63-A : 960-968, July 1981.

6）福島一彦・緒方公介：膝十字靱帯損傷の定量的 $X$ 線 診断法. 整形外科と災害外科, $34: 156-161,1985$.

7) 野沢 進：膝関節十字靶帯損傷時の異常可動性の計 測法とその意義. 整形外科, $24: 797-802,1973$. 
回旋要素の定量的で損傷程度を客観的に判定出来る データを持っていらっしゃるのですか.
解 答
九州大学 福島一彦

大腿骨および脛骨の外顆，外顆の変位量をレ線にて 計測し，回旋の程度を推測するデー夕を，正常膝に関

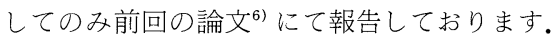

前方引出しのストレスを加えると下腿は内旋します。 その影響は出ませんか.

解 答学福島一彦

回旋の影響に関しては, 今回の発表では検討いたし ておりません。 